\title{
Hypercalcemia due to milk alkali syndrome: An emerging cause of hypercalcemia: A case report and review of literature
}

\author{
Yadav Pandey*1, Krishna Prasad Joshi ${ }^{1}$, Priya Priyambada ${ }^{2}$, Anmol Chaudhary ${ }^{3}$ \\ ${ }^{1}$ Department of Internal Medicine, University of Arkansas for Medical Sciences, Little Rock, AR, USA \\ ${ }^{2}$ Department of Family and Preventive Medicine, University of Arkansas for Medical Sciences, Little Rock, AR, USA \\ ${ }^{3}$ Department of Internal Medicine, Kathmandu Medical College, Nepal
}

Received: April 12, 2018

DOI: $10.5430 /$ crim.v5n2p31
Accepted: May 15, 2018

Online Published: May 16, 2018

\begin{abstract}
Introduction: Hypercalcemia is relatively common in clinical practice. Primary hyperparathyroidism and malignancy accounts for more than 90 percent of all cases of hypercalcemia. Milk alkali syndrome which is hypercalcemia classically caused by ingestion of large amount of calcium and absorbable alkali which was once virtually disappeared as a cause of hypercalcemia has emerged as a third leading cause of hypercalcemia. We present a case of hypercalcemia secondary to ingestion of calcium carbonate tablets resulting in milk alkali syndrome.

Case presentation: Patient is a 45-year-old female with history of gastroesophageal reflux disease came to the emergency department with complaints of dizziness, constipation, fatigue and confusion for 3 weeks. She was hypotensive to $83 / 53 \mathrm{mmHg}$ at arrival. Significant laboratory results were - Potassium of $2.2 \mathrm{mmol} / \mathrm{L}(3.5-5.1 \mathrm{mmol} / \mathrm{L})$, chloride $73 \mathrm{mmol} / \mathrm{L}(98-107 \mathrm{mmol} / \mathrm{L})$, Bicarbonate $50 \mathrm{mmol} / \mathrm{L}$ (22-29 mmol/L), Blood urea $22 \mathrm{mg} / \mathrm{dl}(9.8-20.1 \mathrm{mg} / \mathrm{dl}), \mathrm{Cr} 1.4 \mathrm{mg} / \mathrm{dl}(0.5-1.0 \mathrm{mg} / \mathrm{dl})$, total calcium of $16.6 \mathrm{mg} / \mathrm{dl}$ (9-11 mg/dl), ionized calcium $2.02 \mathrm{mmol} / \mathrm{L}$ (1.15-1.33 mmol/L), PTH was low to $8.9 \mathrm{pg} / \mathrm{ml}$ (10-65 pg/ml). Arterial blood gas showed metabolic alkalosis. Extensive evaluation to find the cause of hypercalcemia was negative. Detailed history after initial stabilization, revealed that she had been taking 10 tablets of calcium carbonate tablets per day and 1 glass of milk daily for reflux symptoms for the last eight weeks. Based on the history and after ruling out all the other serious causes, diagnosis of milk alkali syndrome was made and patient was discharged with proton pump inhibitor with advice to avoid calcium carbonate. Her hypercalcemia responded well to fluid resuscitation.

Conclusions: Milk alkali syndrome once a rare cause of hypercalcemia has emerged as a third leading cause of hypercalcemia in completely different scenario. It is important to evaluate the patient with proper history including the use of over the counter calcium supplements to determine the etiology of hypercalcemia. Our case highlights the importance of proper history taking in the evaluation of hypercalcemia and that not all the cause of severe hypercalcemia is secondary to malignancy.
\end{abstract}

Key Words: Hypercalcemia, Milk-alkali syndrome, Hyperparathyroidism

\footnotetext{
${ }^{*}$ Correspondence: Yadav Pandey; Email: pandey.ydv@ gmail.com; Address: Department of Internal Medicine, University of Arkansas for Medical Sciences, Little Rock, AR, USA.
} 


\section{INTRODUCTION}

Hypercalcemia is relatively common in clinical practice. Primary hyperparathyroidism and malignancy accounts for more than 90 percent of all cases of hypercalcemia. ${ }^{[1-3]}$ Milk alkali syndrome which is hypercalcemia classically caused by ingestion of large amount of calcium and absorbable alkali which was once virtually disappeared as a cause of hypercalcemia has emerged as a third leading cause of hypercalcemia. ${ }^{[4,5]}$ We present a case of hypercalcemia secondary to ingestion of calcium carbonate tablets resulting in milk alkali syndrome.

\section{Case presentation}

Patient is a 45-year-old female with history of gastroesophageal reflux disease came to the emergency department with complaints of dizziness for 3 weeks. History was positive for constipation, fatigue and confusion. She reported loss of appetite and nausea with occasional vomiting for 1 week. She also reported increased frequency of urination and felt like she is dehydrated. She denied any fever, headache, cough, chest pain or shortness of breath. Exam was positive for mild confusion but cardiovascular, respiratory and abdominal examinations were normal. She was hypotensive to $83 / 53 \mathrm{mmHg}$ at arrival which got better after intravenous fluid boluses. Laboratory results showed normal blood counts. Basic metabolic panel showed sodium $137 \mathrm{mmol} / \mathrm{L}$ (136-145 mmol/L), Potassium of $2.2 \mathrm{mmol} / \mathrm{L}$ ( 3.5-5.1 mmol/L), chloride $73 \mathrm{mmol} / \mathrm{L}(98-107 \mathrm{mmol} / \mathrm{L})$, Bicarbonate $50 \mathrm{mmol} / \mathrm{L}(22-29 \mathrm{mmol} / \mathrm{L})$, Blood urea $22 \mathrm{mg} / \mathrm{dl}(9.8-20.1 \mathrm{mg} / \mathrm{dl}), \mathrm{Cr} 1.4 \mathrm{mg} / \mathrm{dl}(0.5-1.0 \mathrm{mg} / \mathrm{dl})$, total calcium of $16.6 \mathrm{mg} / \mathrm{dl}(9-11 \mathrm{mg} / \mathrm{dl})$, ionized calcium $2.02 \mathrm{mmol} / \mathrm{L}(1.15-1.33 \mathrm{mmol} / \mathrm{L})$, serum albumin was $4.4 \mathrm{~g} / \mathrm{dl}(3.5-5.5 \mathrm{~g} / \mathrm{dl}), \mathrm{Mg} 1.3 \mathrm{mg} / \mathrm{dl}$ (1.7-2.2 mg/dl), Phosphorus $2.4 \mathrm{mg} / \mathrm{dl}(2.5-4.5 \mathrm{mg} / \mathrm{dl})$, blood sugar $94 \mathrm{mg} / \mathrm{dl}$. Lactate was $0.9 \mathrm{mmol} / \mathrm{L}$, Arterial blood gas showed metabolic alkalosis with $\mathrm{PH}$ of $7.67, \mathrm{PCO}_{2} 49, \mathrm{PO}_{2} 101$ with $\mathrm{HCO}_{3}$ 56.5. For evaluation of hypercalcemia, $\mathrm{PTH}$ was measured and was found to be low to $8.9 \mathrm{pg} / \mathrm{ml}(10-65 \mathrm{pg} / \mathrm{ml})$. TSH was normal. Urine drug screen was negative. PTH related peptide (PTHrP) was normal to $0.5 \mathrm{pg} / \mathrm{ml}$. 24-hydroxy vitamin D was low to 24.5. 1,25 dihydroxy vitamin D was low to $<5$. CT head done for confusion was negative for acute intracranial lesions and CT chest showed no suspicion of lung mass or sarcoidosis. Serum electrophoresis for light chains was negative. She was initially treated with fluid resuscitation and diuretics after stabilization of blood pressure. Detailed history after initial stabilization, revealed that she had been taking 10 tablets of calcium carbonate tablets per day and 1 glass of milk daily for reflux symptoms for last eight weeks as she was told by a friend that over the counter calcium carbonate is safe and effective for reflux symptoms. Patient was not following anyone as her primary care physician and was not aware of any abnormal labs values. Based on the history and after ruling out all the other serious causes, diagnosis of milk alkali syndrome was made and patient was discharged with proton pump inhibitor with advice to avoid calcium carbonate. Her hypercalcemia responded well to fluid resuscitation.

\section{DisCUSSION}

Malignancy and primary hypoparathyroidism are the two major causes of hypercalcemia. ${ }^{[4]}$ It is often not difficult to differentiate between these two, as malignancy is often evident by the time it causes hypercalcemia. Calcium level in malignancy is much higher than in primary hypoparathyroidism. Malignancy is the most common cause of hypercalcemia in the inpatient setting occurring in the patients with both solid tumors and hematologic malignancies. ${ }^{[6]}$ There are 3 major mechanisms for hypercalcemia of malignancy production of parathyroid hormone related protein (PTHrP), osteolytic metastasis resulting in release of cytokines locally and production of calcitriol by tumor cells. ${ }^{[7]}$ In primary hyperparathyroidism patient, often present with asymptomatic hypercalcemia and elevated calcium as an incidental finding. ${ }^{[8]}$ Hypercalcemia in primary hyperparathyroidism is due to parathyroid hormone-mediated activation of osteoclast leading to bone resorption.

Milk alkali syndrome consisting of a classic triad of hypercalcemia, metabolic alkalosis and acute kidney injury has emerged as a third common cause of hypercalcemia. ${ }^{[4]}$ Historically, milk alkali syndrome was caused by the use of milk and sodium bicarbonate for the treatment of peptic ulcer disease. ${ }^{[9,10]}$ The occurrence of milk-alkali syndrome had dramatically reduced with the use of more effective non-alkali therapies for peptic ulcer disease like proton pump inhibitors and $\mathrm{H} 2$ blockers. ${ }^{[11]}$ However, recently the incidence has increased secondary to the use of calcium carbonate to minimize secondary hyperphosphatemia in patients with chronic kidney disease and use of calcium therapy for prevention as well as treatment of osteoporosis. ${ }^{[4,5]}$ In addition, due to the easy availability of the over the counter calcium containing antacids, incidence of calcium alkali syndrome has increased. Due to change in cause and epidemiology over time, many authors prefer to use the terminology calcium-alkali syndrome instead of milk-alkali syndrome. ${ }^{[12]}$ Currently, almost $12 \%$ of the hypercalcemia is contributed to milk-alkali syndrome. ${ }^{[5]}$

Although milk alkali syndrome is caused by ingestion of calcium with absorbable alkali, only few patients taking large amount of calcium carbonate develop sustained hyper- 
calcemia and metabolic alkalosis with kidney injury. ${ }^{[9,13]}$ Various mechanisms play important role to prevent hypercalcemia in patients with excessive intake. Reduced calcium absorption due to suppressed vitamin $\mathrm{D}^{[14]}$ and buffering of excess calcium by bone ${ }^{[15]}$ are the important ones. It is unclear why only some individuals are affected by excessive intake. Such individuals tend to have increased absorption and failure in suppression of calcitriol in response to hypercalcemia. ${ }^{[16]}$ Age plays an important role; older individuals tend have a reduced bone-buffering capacity which put them at higher risk for hypercalcemia. ${ }^{[17]}$ Hypercalcemia in milk alkali syndrome tends to maintain itself by volume depletion by diuresis and natriuresis; decreased GFR leading to decreased filtration of calcium via kidney and increased renal reabsorption of calcium due to metabolic alkalosis ${ }^{[18]}$ (see Figure 1). Historically, milk alkali syndrome seen during the treatment of peptic ulcer with Sippy regimen caused hyperphosphatemia due to ingestion of phosphorus rich milk. However, ingestion of calcium carbonate without milk for treatment of osteoporosis or self-treatment of dyspepsia with cause low to normal hypophosphatemia due phosphate binding property of calcium carbonate and absence of phosphate loading. ${ }^{[4,18]}$ Hypophosphatemia is more common in elderly patient probably secondary to reduced ingestion of dietary phosphorus. ${ }^{[19]}$ Interestingly in our case, patient was taking one glass of milk every day which might have prevented her from developing severe hypophosphatemia.

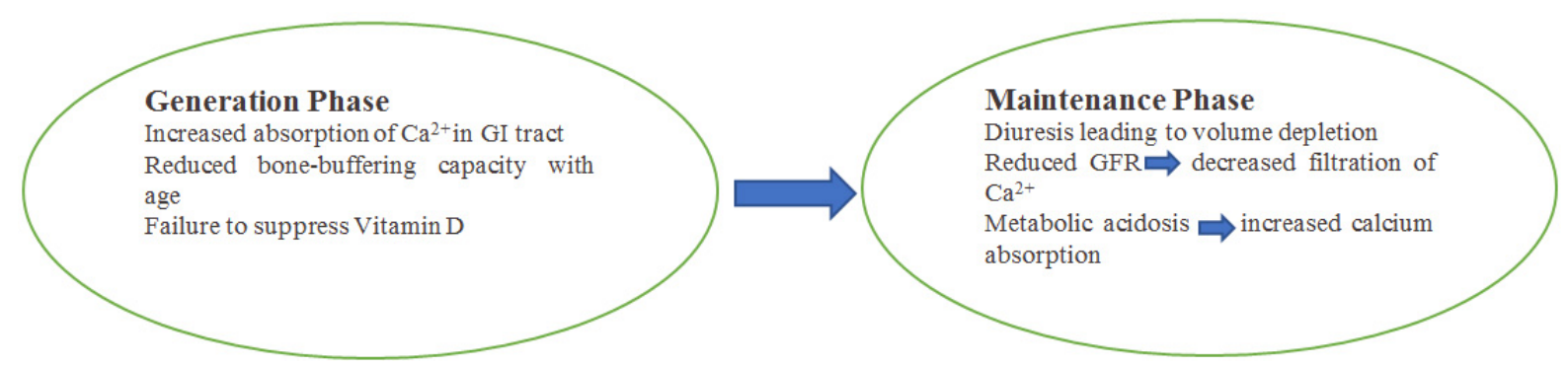

Figure 1. Mechanism showing generation and maintenance of hypercalcemia in milk alkali syndrome ${ }^{[18]}$

Clinical manifestation of hypercalcemia can range from asymptomatic incidental finding to obtundation and coma. ${ }^{[20]}$ Depending upon the level of serum calcium and chronicity, patient can present with the milder symptoms like fatigue, constipation, nausea to more severe symptoms like polyuria, polydipsia, dehydration, anorexia, muscle weakness and confusion. ${ }^{[20,21]}$ Neuropsychiatric disturbances like depression, anxiety and cognitive dysfunction is also common in patient with chronic hypercalcemia. In rapidly progressing hypercalcemia, patient can present with more severe symptoms like lethargy, altered sensorium, stupor and coma. ${ }^{[4,21]}$ Similarly, in hypercalcemia due to milk alkali syndrome, patients are often asymptomatic and abnormal lab finding of elevated calcium, alkalosis and renal dysfunction is an incidental finding. Other common lab findings are hypophosphatemia secondary to phosphate-binding property of calcium carbonate and hypomagnesemia due to hypercalcemia-induced inhibition of magnesium reabsorption by renal tubules. ${ }^{[5]}$ Reduced PTH level helps to distinguish the milk alkali syndrome from primary hyperparathyroidism. ${ }^{[16]}$

Stopping the offending agent along with hydration with isotonic saline and furosemide is the mainstay of treatment of milk alkali syndrome. ${ }^{[22]}$ In milk alkali syndrome, there is chronically suppressed PTH due to chronic hypercalcemia which is an important point to consider during treatment of hypercalcemia in milk alkali syndrome. As a result, hypocalcemia is often common after treatment. ${ }^{[4]}$ For the same reason, bisphosphonates should be avoided in the treatment of hypercalcemia, which can result in prolonged suppression of serum calcium and exacerbate hypocalcemia. ${ }^{[5]}$

\section{Conclusion}

Milk alkali syndrome once a rare cause of hypercalcemia has emerged as a third leading cause of hypercalcemia in completely different scenario. It is important to evaluate the patient with proper history including the use of over the counter calcium supplements to determine the etiology of hypercalcemia. Use of more effective proton pump inhibitor and $\mathrm{H} 2$ blockers helps to reduce the risk of hypercalcemia. Our case highlights the importance of proper history taking in the evaluation of hypercalcemia and not all the cause of severe hypercalcemia is secondary to malignancy.

\section{CONFLiCTS OF INTEREST Disclosure}

The authors declare no conflicts of interest. 


\section{REFERENCES}

[1] Lafferty FW. Differential diagnosis of hypercalcemia. J Bone Miner Res. 1991 Oct; 6 Suppl 2: S51-9; discussion S61.

[2] Burtis WJ, Wu TL, Insogna KL, et al. Humoral hypercalcemia of malignancy. Ann Intern Med. 1988 Mar; 108(3): 454-7. PMid:3277518. https://doi.org/10.7326/0003-4819-108-3-454

[3] Ratcliffe WA, Hutchesson AC, Bundred NJ, et al. Role of assays for parathyroid-hormone-related protein in investigation of hypercalcaemia. Lancet (London, England). 1992 Jan; 339(8786): 164-7. https : //doi .org/10.1016/0140-6736(92)90220-W

[4] Beall DP, Scofield RH. Milk-alkali syndrome associated with calcium carbonate consumption. Report of 7 patients with parathyroid hormone levels and an estimate of prevalence among patients hospitalized with hypercalcemia. Medicine (Baltimore). 1995 Mar; 74(2): 8996. https://doi.org/10.1097/00005792-199503000-00004

[5] Picolos MK, Lavis VR, Orlander PR. Milk-alkali syndrome is a major cause of hypercalcaemia among non-end-stage renal disease (nonESRD) inpatients. Clin Endocrinol (Oxf). 2005 Nov; 63(5): 566-76. PMid:16268810. https : //doi .org/10.1111/j.1365-2265.20 $05.02383 . x$

[6] Stewart AF. Clinical practice. Hypercalcemia associated with cancer. N Engl J Med. 2005 Jan; 352(4): 373-9. PMid:15673803. https://doi.org/10.1056/NEJMcp042806

[7] Mirrakhimov AE. Hypercalcemia of Malignancy: An Update on Pathogenesis and Management. N Am J Med Sci. 2015 Nov; 7(11) 483-93. PMid:26713296. https ://doi .org/10.4103/1947-271 4.170600

[8] Silverberg SJ, Lewiecki EM, Mosekilde L, et al. Presentation of asymptomatic primary hyperparathyroidism: proceedings of the third international workshop. J Clin Endocrinol Metab. 2009 Feb 94(2): 351-65. PMid:19193910. https://doi.org/10.1210/jc .2008-1760

[9] JB K, PALMER W. Alkalosis complicating the sippy treatment of peptic ulcer: An analysis of one hundred and thirty-five episodes. Arch Intern Med [Internet]. 1942 May 1; 69(5): 789-807. https: //doi.org/10.1001/archinte.1942.00200170071006

[10] Sippy BW. Landmark article May 15, 1915: Gastric and duodenal ulcer. Medical cure by an efficient removal of gastric juice corrosion. By Bertram W. Sippy. JAMA. 1983 Oct; 250(16): 2192 7. PMid:6352976. https://doi.org/10.1001/jama.1983.03 340160078040
[11] Jamieson MJ. Hypercalcaemia. Br Med J (Clin Res Ed). 1985 Feb; 290(6465): 378-82. https ://doi.org/10.1136/bmj . 290.6465 .378

[12] Patel AM, Adeseun GA, Goldfarb S. Calcium-Alkali Syndrome in the Modern Era. Nutrients [Internet]. 2013 Dec; 5(12): 4880-93. PMid:24288027. https : //doi.org/10.3390/nu5124880

[13] Kapsner P, Langsdorf L, Marcus R, et al. Milk-alkali syndrome in patients treated with calcium carbonate after cardiac transplantation. Arch Intern Med. 1986 Oct; 146(10): 1965-8. PMid:3532984. https : //doi.org/10.1001/archinte.1986.00360220119021

[14] Adams ND, Gray RW, Lemann JJ. The effects of oral CaCO3 loading and dietary calcium deprivation on plasma 1,25-dihydroxyvitamin D concentrations in healthy adults. J Clin Endocrinol Metab. 1979 Jun; 48(6): 1008-16. PMid:571872. https ://doi .org/10.1210/ jcem-48-6-1008

[15] Matkovic V. Calcium metabolism and calcium requirements during skeletal modeling and consolidation of bone mass. Am J Clin Nutr. 1991 Jul; 54(1 Suppl): 245S-260S. PMid:2053570. https : //doi.org/10.1093/ajcn/54.1.245S

[16] Medarov BI. Milk-alkali syndrome. Mayo Clin Proc. 2009 Mar; 84(3): 261-7. PMid:19252114. https://doi.org/10.4065/84 .3. 261

[17] Patel AM, Goldfarb S. Got calcium? Welcome to the calciumalkali syndrome. J Am Soc Nephrol. 2010 Sep; 21(9): 1440-3. PMid:20413609. https ://doi .org/10.1681/ASN . 2010030255

[18] Felsenfeld AJ, Levine BS. Milk alkali syndrome and the dynamics of calcium homeostasis. Clin J Am Soc Nephrol. 2006; 1(4): 641-54. PMid:17699269. https://doi.org/10.2215/CJN.01451005

[19] Lorenzo V, Martin M, Rufino M, et al. Protein intake, control of serum phosphorus, and relatively low levels of parathyroid hormone in elderly hemodialysis patients. Am J Kidney Dis. 2001 Jun; 37(6): 1260-6. PMid:11382697. https ://doi .org/10.1053/ajkd. 200 1.24532

[20] Shane E, Dinaz I. Hypercalcemia: pathogenesis, clinical manifestations, differential diagnosis, and management. Prim Metab Bone Dis Disord Miner Metab. 2006; 176-80.

[21] Inzucchi SE. Understanding hypercalcemia. Its metabolic basis, signs, and symptoms. Postgrad Med. 2004 Apr; 115(4): 69-76.

[22] Hosking DJ, Cowley A, Bucknall CA. Rehydration in the treatment of severe hypercalcaemia. Q J Med. 1981; 50(200): 473-81. PMid:7342172. 